\title{
Taguchi-Grey relation analysis for assessing the optimal set of control factors of thermal barrier coatings for high-temperature applications
}

\author{
Mohammed Yunus*, Mohammad S. Alsoufi and Shadi M. Munshi
}

\begin{abstract}
Background: In an aerospace industry, the efficient use of thermally sprayed coatings for high-temperature applications is achieved by improving the thermal characteristics (TC) such as thermal drop/barrier (TD) and thermal fatigue cycles (TFC). The characterization of ceramic coatings demands a better understanding of TC and their performance.

Methods: In this paper, an attempt has been made to use hybrid Taguchi design method based grey relation analysis (GRA) for optimizing the control factors such as the thickness of coating, type of coating, bond coating and exposed temperature. The necessary experiments were carried out using Taguchi L16 factorial design of experiments for analysis based on the larger the better signal-to-noise $(\mathrm{S} / \mathrm{N})$ ratio. The multi-response/output optimization and grading of control factors were successfully carried out by GRA.

Results: The significance of each factor as regards TD and TFC were investigated. The ANOVA results showed that most important parameters at $95 \%$ confidence level and were validated with a confirmation test using optimum process factors. It shows an improvement in the TC of thermal barrier coatings.

Conclusions: This work revealed that the hybrid GRA with Taguchi technique had improved the durability and efficient usage of TBC for high-temperature applications.
\end{abstract}

Keywords: Thermal characteristics, Thermal drop, Hybrid Taguchi-Grey, Ceramic coatings, ANOVA

\section{Background}

The preparation of an engineering surface to withstand severe working conditions such as high temperature, corrosive environment, excessive wear and so on demands suitable surface modification techniques for existing materials and alloys by coating with thermally sprayed industrial ceramic coatings (Gibson et al. 2013; Javadi et al. 2014; Koilraj et al. 2012; Lakshminarayanan and Balasubramanian 2007; Pan et al. 2007; Yunus and Alsoufi 2016). Thermal barrier coatings (TBC) are ceramic oxide coatings applied to the metal substrate and are widely used in aerospace, automobiles, gas turbines, and power generators and so on in order to increase the

\footnotetext{
* Correspondence: Yunus.mohammed@rediffmail.com

Department of Mechanical Engineering, College of Engineering and Islamic Architecture, Umm Al-Qura University, Makkah, Kingdom of Saudi Arabia
}

life of engineering materials. TBCs, due to their low thermal conductivity, act as an insulator and protect the metal substrate from high temperature as well as the corrosive environment. Generally, TBCs consist of a pair of layers: the first layer is a metallic bond coat to protect the metal substrate from corrosion, oxidation and as well as increases adhesive intensity with a coating layer, whereas the second layer is ceramic oxide coating protects metal from high temperature as well as from excessive wear and corrosion. The TBCs are generally applied on the substrate of a metal substrate. The desirable properties of these include high thermal expansion, low thermal conductivity and excellent thermal cycling resistance. In a complex and multivariate performance systems such as engineering design and material characterization system, where many parameters 
simultaneously influence the system to determine their state of development. Typically, we want to know the parameters which affect the system more or little. However, a relationship between various parameters is usually grey due to unclear, incomplete and uncertain information. Moreover, difficult to obtain practical and experimental data due to scattered too much to analyze. Two conventional statistical techniques (factor and regression analysis) frequently used on the data consisting of the relationship between dependent and independent parameters. However, these analyses prescribe mutual influence between variables, the large volume of data and should conform to the typical distribution. However, usually, difficult to obtain the internal factors relationship data. Therefore, traditional multivariate statistical methods possess a hard time in getting a convincing explanation. Therefore, a new analysis method needs to be addressed to overcome the disadvantages of regression and factor analysis and multi-response method. Grey relational analysis (GRA) has been recommended to solve our problem, a kind of efficient tool to perform system analysis, lays a framework for modelling, forecasting, and clustering of grey systems. Grey relational has the many advantages such as small sample having no typical distribution, no requirement of independent variables and a small amount of calculation. Additionally, GRA analysis is already proved to be a straightforward and accurate method for selecting parameters for those problems with unique characteristics (Gibson et al. 2013; Javadi et al. 2014; Koilraj et al. 2012; Lakshminarayanan and Balasubramanian 2007; Mishra and Ma 2005; Pan et al. 2007; Yunus and Alsoufi 2015). Therefore, the present study will utilize the GRA to establish grey relational grade (GRG with a ranking scheme to place the series of the grey relationship between both independent and dependent parameters. GRA is a judgment model for deciding influential parameters in multi-output systems using rearranged GRG according to their magnitude order. Table 1 provides the control parameters and their levels adopted for studying the application of industrial ceramic

Table 1 Process parameters and their levels for thermal characteristics of coatings

\begin{tabular}{|c|c|c|c|c|c|}
\hline \multirow[t]{2}{*}{ Process parameters } & \multirow[t]{2}{*}{ Symbols } & \multicolumn{4}{|c|}{ Parameters levels } \\
\hline & & $\begin{array}{l}\text { Level } \\
\text { (1) }\end{array}$ & $\begin{array}{l}\text { Level } \\
\text { (2) }\end{array}$ & $\begin{array}{l}\text { Level } \\
\text { (3) }\end{array}$ & $\begin{array}{l}\text { Level } \\
\text { (4) }\end{array}$ \\
\hline Coating Type & A & $A$ & AT & PSZ & Super-Z \\
\hline Coating Side Temperature, ${ }^{\circ} \mathrm{C}$ & $\mathrm{T}$ & 700 & 800 & 900 & 1000 \\
\hline Coating Thickness, $\mu \mathrm{m}$ & C & 100 & 150 & 225 & 300 \\
\hline Bond Coating Thickness, $\mu \mathrm{m}$ & B & 50 & 75 & 100 & 150 \\
\hline
\end{tabular}

TBCs. Tests were conducted using Taguchi L16 orthogonal array.

\section{Grey relational analysis (GRA)}

Deng Julong et al. presented the GRA approach (Cavaliere et al. 2008) for estimating the magnitude of the relationship between arrays of experiments using GRG. GRA is employable in the optimization of control factors having multi-performances/responses/outputs through the GRG (Cavaliere et al. 2008). Mostly, GRA is successfully utilized in a process with limited or inadequate information (Fig. 1). Various stages involved in the GRA technique are:

Step No.1: Normalizing or data preprocessing would be the initial step conducted to normalize (transforming measured units into dimensionless parameters) the test results on the scale of zero and one due to the series of the degree of the process factors are different (Cavaliere et al. 2008; Lin 2002). In this grey relational generating step, initial series are changed into a collection of comparable series. Several methods are available to preprocess the grey data. In this work, Taguchi design method based GRA used to optimize TC of TBCs at high-temperature application parameters for multiple response quality features such as TD and TFC to withstand high temperature in studying the amount of barrier offered (temperature drop occurring across the coating) and lifespan of coatings over the metal substrate. Multiple objective features were depending upon the quality characteristics of the initial data. It represents the initial ideal array and preprocessed data (compatibility series) by $z_{j}^{*}(h) z_{j}^{0}(h), j=1,2,3, \ldots, u ; h=1,2,3, \ldots, v$, where $u$ and $v$ are the number of trials and data observations, respectively. Moreover, on the quality features of original data, the principal divisions identified for normalizing the initial series using either Eq. (1) for "smaller-the-better" or Eq. (2) for "larger-the-better" (Sharma et al. 2005):

$$
\begin{aligned}
& z_{j}^{*}=\frac{\max z_{j}^{0}(h)-z_{j}^{0}(h)}{\max z_{j}^{0}(h)-\min z_{j}^{0}(h)} \\
& z_{j}^{*}(h)=\frac{z_{j}^{0}(h)-\min z_{j}^{0}(h)}{\max z_{j}^{0}(h)-\min z_{j}^{0}(h)}
\end{aligned}
$$

where, $\max z_{\mathbf{j}}^{0}(\mathrm{~h})$ and $\operatorname{minz}_{\mathbf{j}}^{0}(\mathrm{~h})$ are the greatest and least values of $z_{j}^{0}(h)$, the series after the data processing (or compatibility series) and $z_{j}^{*}(h)$ is the original series of the target/end value. In the present analysis, $u=16$ and $v=2$ are used.

Step No.2: Calculate the grey relational coefficient (GRC) using the deviation coefficient from Eq. (3). Deviation coefficient is defined as the arbitrary value 


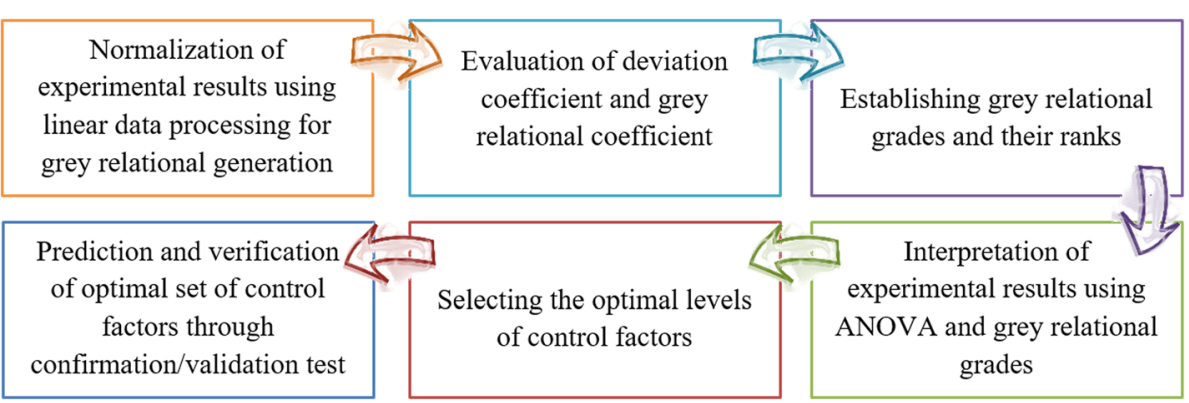

Fig. 1 Steps involved in hybrid GRA based on Taguchi method

of the variation between the compatibility and reference series:

$$
\Delta_{j}^{o}(h)=z_{j}^{0}(h)-z_{j}^{*}(h)
$$

where, $\Delta_{j}^{o}(h)$ is the deviation coefficient, $z_{j}^{*}(h)$ is the ideal series (or reference series) and $z_{j}^{0}(h)$ is the compatible series. The GRC is then determined using Eq. (4):

$$
\gamma==\underbrace{\left(z_{0}^{*}\left(h \times z_{j}^{*}(h)\right)\right)}_{\text {GRC (between } 0 \text { and } 1)}=\frac{* \Delta_{\min }+\varsigma \cdot \Delta_{\max }}{\Delta_{j}^{o}(h)+\varsigma \cdot \Delta_{\max }}
$$

Step No.3: Calculate the GRGs $\gamma\left(z_{0}^{*} \cdot z_{j}^{*}\right)$ is obtained by the weighted sum of the $\zeta$ GRC which represents the level of relationship between ideal and compatible series and evaluated using Eq. (5):

$$
\gamma\left(z_{0}^{*} \cdot z_{j}^{*}\right)=\frac{1}{N} \gamma\left(z_{0}^{*}(h) \cdot \gamma\left(z_{j}^{*}(h)\right)\right)
$$

Step No.4: Ranking of GRG where GRGs are sequenced in decreasing order to obtain the higher/leading value of the GRG which represents substantial correlation degree between the ideal and the compatible series. The maximum value of the GRG represents the optimal mixture/blend of process parameters for the aspired outputs.

\section{Experimental methodology}

In this wok, all experiments have been carried out on mild steel flat specimens coated with atmospheric plasma spraying method using commercial industrial ceramic coating powder materials operated at optimum spray parameters. Alumina $\left(\mathrm{Al}_{2} \mathrm{O}_{3}\right)$, Alumina-Titania $\left(\mathrm{Al}_{2} \mathrm{O}_{3}+\mathrm{TiO}_{2}\right)$, Super-Z alloy $\left(20 \% \mathrm{Al}_{2} \mathrm{O}_{3}+80 \% \mathrm{PSZ}\right)$ and partially stabilized zirconia (PSZ) and of varying coating thicknesses (100 to $300 \mu \mathrm{m})$ were used for the preparation of different coating surfaces. Using $40 \mathrm{KW}$ Sulzer, Metco plasma spray with a seven MB gun; coating powders sprayed on the substrate which was grit blasted, degreased as well as applied with an alloy layer of $\mathrm{NiCrAl}$ bond coat of 50 to $100 \mu \mathrm{m}$ thickness according to the spray parameters.

The experimentation on thermal characteristics was carried out using a high-temperature flame to estimate temperature drop across the thickness of coating called thermal drop (TD) and a number of cycles withstood known as thermal fatigue cycles (TFC) (Lakshminarayanan and Balasubramanian 2007). Four levels for every process parameter were selected without taking the parametric interaction effect into consideration. The control factors considered were the type of coating powder (A), the temperature on coating side $(\mathrm{T})$, coating thickness $(\mathrm{C})$ and bond coat thickness (B). The numerical values of control factors at various levels are depicted in Table 1. In multi-output optimization, it is always expected that there is some loss in quality characteristics when compared to a single-output optimization to always improve the overall quality. The proper adoption of various process factors and their assigned levels that stir these quality characteristics will enhance TCs. The graded characters examined were TD and TFC. The Taguchi design methodology for four factors of four levels is used to implement the system of the orthogonal array (OA) trials/ experiments. An L16 OA having $16 \times 4$ array is utilized in the current work. The trials are conducted according to the pattern of the $\mathrm{OA}$ and the output values are obtained provide in Table 2.

\section{Thermal drop/barrier test (TD)}

Thermal drop tests were carried out by measuring the temperature of a metal substrate before and after heating the coating side surface in the range of 700 and $1000{ }^{\circ} \mathrm{C}$ for about 20 to $30 \mathrm{~min}$ to reach steady state. Temperature drop across the substrate and ceramic coating are noted down. A pair of thermocouples of chrome-alumel type (K-type) has been used for measuring the temperature between the metal surface and ceramic coated surface for a given heat input value. The obtained temperature 
Table 2 Experimental output results and data processing of TC of TBCs

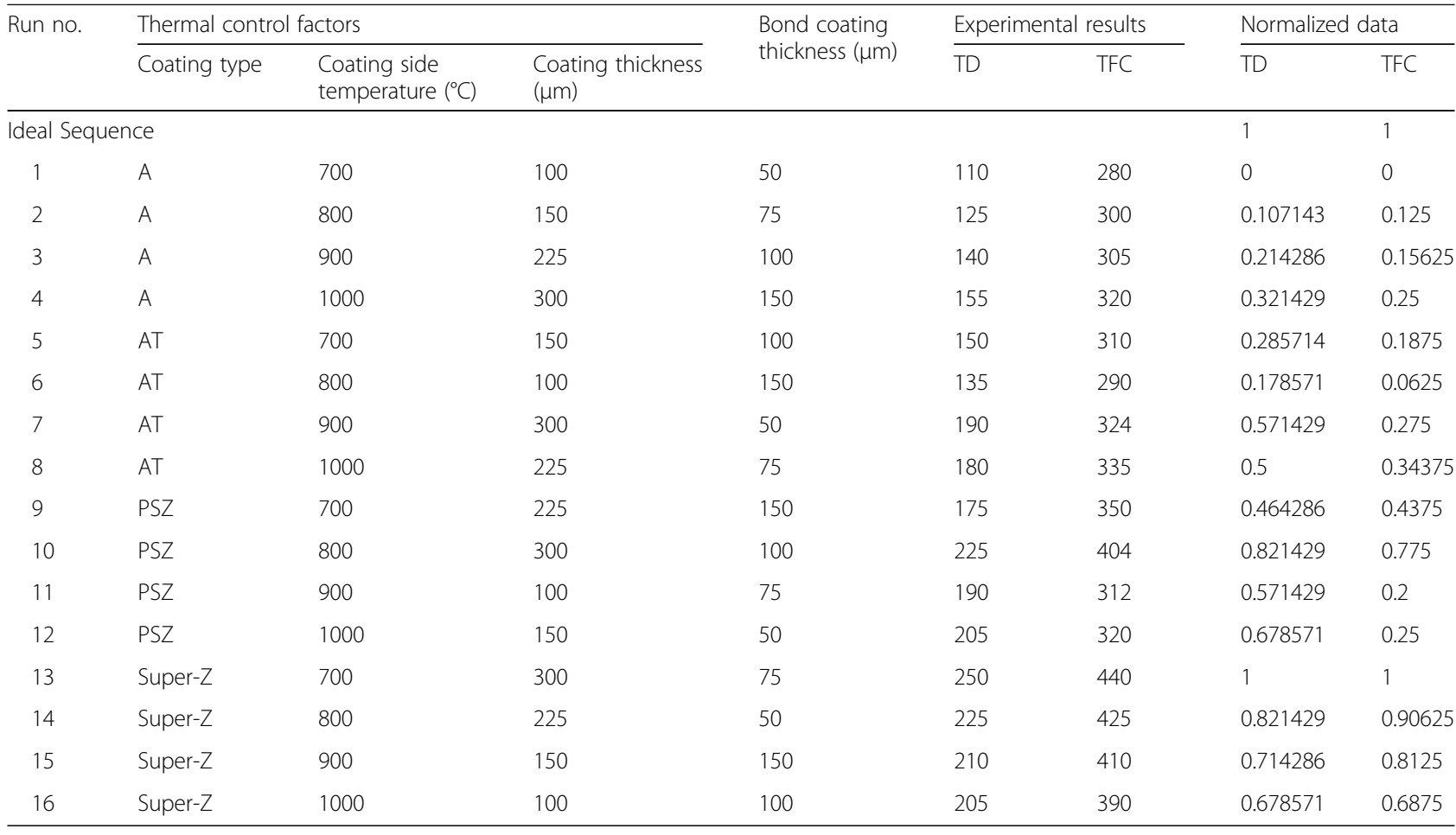

difference values are measured for L16 OA as shown in Table 2 (Koilraj et al. 2012).

\section{Thermal fatigue cycling (TFC) test}

A thermal fatigue cycling test is carried out to investigate the resistance or strength of coating as regards sudden changes in temperature (heating and cooling) (Javadi et al. 2014; Koilraj et al. 2012; Lakshminarayanan and Balasubramanian 2007; Mishra and Ma 2005) and to examine the withstanding of the sprayed coatings under the severity of thermal cycling. The TBCs were subjected to thermal fatigue cycles by heating the coated surface to an oxyacetylene flame until it reaches approximately $1000{ }^{\circ} \mathrm{C}$ temperature for about one minute and subsequently cooled down by air blow until the temperature drops to around $30{ }^{\circ} \mathrm{C}$ in the atmospheric conditions for about one minute. The TFC process will be repeated until the coated surface fails and peels off from the substrate to determine the number of cycles it withstood as detailed in Table 3.

\section{Results and discussion}

Multi-response optimization of control factors using GRA The performance of thermal characteristics is decided from the maximum value of TD and TFC of TBCs. Also, TD and TFC are selected "higher-the-better" type for normalization in GRA approach. We used Taguchi's
L16 OA to optimize the multiple-response of thermal characteristics of TBC to propose their use in the field of higher temperature applications. Thus, the data series have "larger-the-better" TCs. The "larger-thebetter" methodology using Eq. (2), was employed for data pre-processing (Das et al. 2014). The normalized values of TD and TFC are given in Table 3. The GRC (shown in Table 4) of TD and TFC was computed using Eq. (4) by the deviation sequences obtained from Eq. (3). All the control factors have equal weighting and set at 0.5 . Next, the weight of both responses has been used to compute the GRG by using Eq. (5), for each trial are given in Table 4 (El-Gallab and Sklad 1998). Precise observations from Table 4 and Fig. 2, indicate that trial number 13 has the excellent performance for both responses TD and TFC between all experiments as the larger GRG mean the comparable sequence is exhibiting a stronger correlation with the ideal series (Singh and Kumar 2004). GRA was employed to find the highest significant parameter based on the hypothesis that a mixture of the levels provides the greatest average response and is the optimal parameters combination to increase the lifespan of TBC for high-temperature applications. From maximum average GRG, optimum parameter level has been found as A4T1C4B2, i.e., Super-Z coating material, heating of coating at $700{ }^{\circ} \mathrm{C}, 300 \mu \mathrm{m}$ coating thickness and $75 \mu \mathrm{m}$ bond coat thickness. Response tables were generated using the Taguchi design method to evaluate the 
Table 3 Deviation and grey relational coefficients of thermal characteristics of TBCs

\begin{tabular}{|c|c|c|c|c|}
\hline \multirow[t]{2}{*}{ Run no. } & \multicolumn{2}{|c|}{ Deviation coefficient } & \multicolumn{2}{|c|}{ Grey relational coefficient } \\
\hline & $\mathrm{TD}$ & TFC & $\mathrm{TD}$ & TFC \\
\hline Ideal Sequence & & & 1 & 1 \\
\hline 1 & 1 & 1 & 0.333333 & 0.333333 \\
\hline 2 & 0.89285714 & 0.875 & 0.358974 & 0.363636 \\
\hline 3 & 0.78571429 & 0.84375 & 0.388889 & 0.372093 \\
\hline 4 & 0.67857143 & 0.75 & 0.424242 & 0.4 \\
\hline 5 & 0.71428571 & 0.8125 & 0.411765 & 0.380952 \\
\hline 6 & 0.82142857 & 0.9375 & 0.378378 & 0.347826 \\
\hline 7 & 0.42857143 & 0.725 & 0.538462 & 0.408163 \\
\hline 8 & 0.5 & 0.65625 & 0.5 & 0.432432 \\
\hline 9 & 0.53571429 & 0.5625 & 0.482759 & 0.470588 \\
\hline 10 & 0.17857143 & 0.225 & 0.736842 & 0.689655 \\
\hline 11 & 0.42857143 & 0.8 & 0.538462 & 0.384615 \\
\hline 12 & 0.32142857 & 0.75 & 0.608696 & 0.4 \\
\hline 13 & 0 & 0 & 1 & 1 \\
\hline 14 & 0.17857143 & 0.09375 & 0.736842 & 0.842105 \\
\hline 15 & 0.28571429 & 0.1875 & 0.636364 & 0.727273 \\
\hline 16 & 0.32142857 & 0.3125 & 0.608696 & 0.615385 \\
\hline
\end{tabular}

average value of the GRG for each process parameter level, as illustrated in Table 5 for thermal characteristics of TBC coatings.

Table 5 shows the greatest values of GRG obtained for the combination of A4-T3-C4-B2. It depicts the optimal combination of TBC control factors for the multiple outputs of TC during estimation of lifespan for hightemperature applications. A4-T3-C4-B2 combination indicates the type of coating of Super- $\mathrm{Z}$ alloy, the temperature on coating side of $1000{ }^{\circ} \mathrm{C}$, Coating thickness of $300 \mu \mathrm{m}$ and bond coat thickness of $75 \mu \mathrm{m}$. The main effect plots for means of GRG are shown in Fig. 2. The dashed lines in the main effect plots describe the total average of the GRG. Figure 3 reveals the different residual plots of

Table 4 GRG response tables and their order

\begin{tabular}{ccllll}
\hline Run no. & Grey relational grade & Order & Run no. & Grey grade & Order \\
\hline 1 & 0.333333 & 16 & 9 & 0.476673 & 7 \\
2 & 0.361305 & 15 & 10 & 0.713249 & 3 \\
3 & 0.380491 & 13 & 11 & 0.461538 & 10 \\
4 & 0.412121 & 11 & 12 & 0.504348 & 6 \\
5 & 0.396359 & 12 & 13 & 1 & 1 \\
6 & 0.363102 & 14 & 14 & 0.789474 & 2 \\
7 & 0.473312 & 8 & 15 & 0.681818 & 4 \\
8 & 0.466216 & 9 & 16 & 0.61204 & 5 \\
\hline
\end{tabular}

GRG which are evaluated to understand the effectiveness of method used in the optimization (Mohammed and Rahman 2011).

\section{Analysis of variance (ANOVA) for GRG}

ANOVA is employed to determine the grades or ranks of GRA at $95 \%$ confidence level for investigating the significance level of control factors on multiple TC of TBC Coatings at high-temperature applications using Minitab ${ }^{\odot} 17$ statistical software (Sato and Kokawa 2003). A total sum of squared variances $\left(\mathrm{SS}_{\mathrm{T}}\right)$ can be estimated using Eq. (6):

$$
\mathrm{SS}_{T}=\sum_{\mathrm{j}=1}^{\mathrm{N}}(\mathrm{yj}-\mathrm{ym})^{2}
$$

where, $N=$ number of trials in the OA, $y_{j}=$ mean of GRG for $j^{\text {th }}$ trial and $y_{m}=$ total average of GRG. Mean square $(M S)$ can be obtained by dividing the $S S$ by the corresponding degree of freedom $(D F)$, i.e.,

$$
M S=\frac{S S}{D F}
$$

The most/principal significant process parameter (significant influence on the output attributes) is one which has a higher $F$ value (or smaller $P$ value). The percentage contribution of a parameter can be evaluated by dividing $S S_{T}$ with the corresponding $S S$, as presented in Eq. (8). There is also a residual plot for GRG (Khalid 2005).

$$
\% \text { of contribution }=\frac{S S_{T}}{S S} \times 100
$$

The ANOVA results for GRG of TBCs have been given in Table 6. It is seen that only the coating type played most significant thermal control factor for TD and TFC considered simultaneously during high temperature applications of TB coatings. The percentage of contribution control factor of the type of coating for the multi-response thermal characteristics of TBCs is 72.98.

\section{Verification of results using confirmation/ratification test}

The optimal set of factors combination in achieving maximum TD and TFC is obtained using Taguchi based GRA as A4-T3-C4-B2. A confirmation test was carried out by using an A4-T3-C4-B2 optimal setting. The results of the verification test were $265^{\circ} \mathrm{C}$ for TD (temperature fall from coating side to substrate side) and TFC of 466 (number of cycles withstood). The validation test result is observed better than the experiments carried out in Table 3. Once, we find an optimal combination of TC process parameters and the principal significant parameter for TD and TFC of $\mathrm{TBC}$, the final step would be to verify the practicability of proposed Taguchi design method based GRA by carrying out some validation tests. The optimum GRG, $\Gamma_{o p t}$, is computed as (Khalid 2005): 


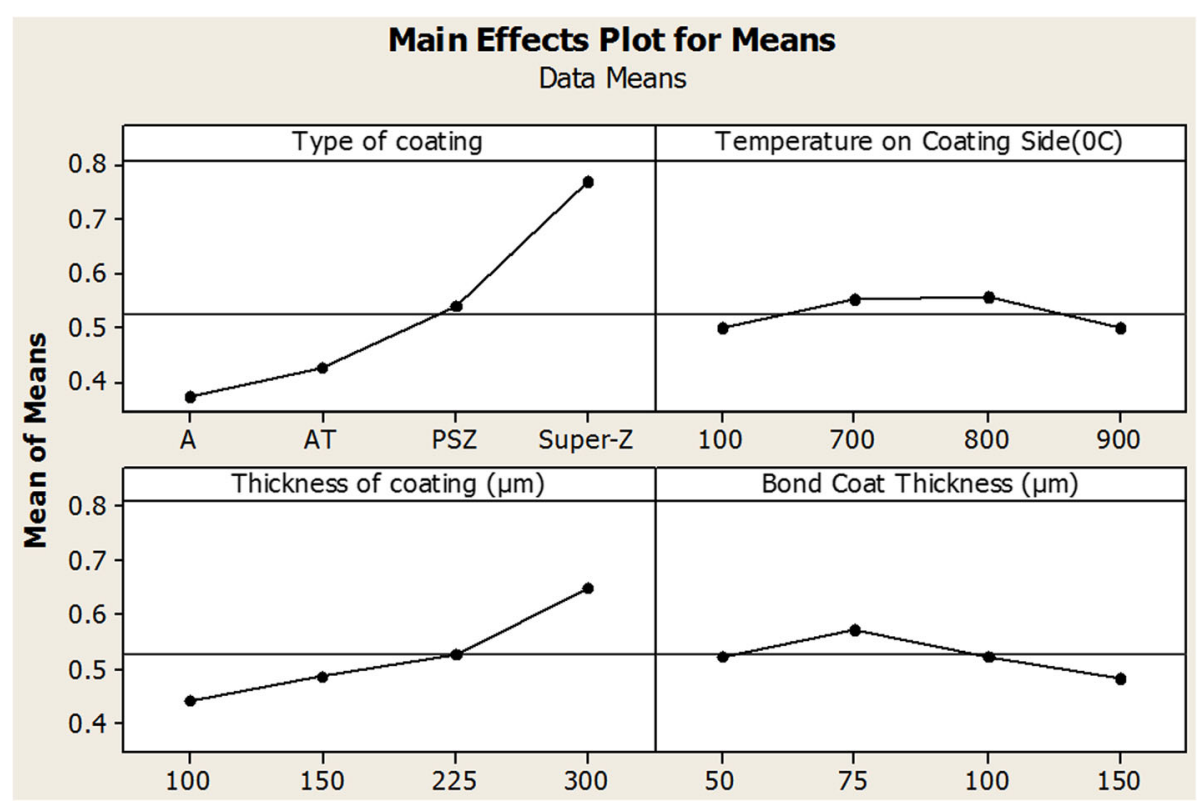

Fig. 2 Total mean of GRG vs. process parameters

$$
\beta_{\text {opt }}=\beta_{m}+\sum_{i=1}^{c}\left(\beta_{i}-\beta_{m}\right)
$$

where, $\beta_{m}$ is the total average of the GRG, $\beta_{i}$, is the average of the GRG of $i^{\text {th }}$ factor at the optimum level, and $c$ is the number of largest significant TBC control factors (Khalid 2005). In both cases, the values of TD and TFC for an optimal combination of control factors were adequately larger as compared to those of initial set of process parameters and equal to 0.8168. Additional experiments are performed at optimum levels of parameters and the average of additional experimental results is taken for the verification/confirmation test. Table 7 provides the predicted value of GRG and corresponding validation test results. It is noticed that TBC characteristics viz. TD is elevated from 226 to $265{ }^{\circ} \mathrm{C}$ and TFC is improved from 431 to 466 numbers of cycles withstood.

\section{Conclusions}

Thermal characteristics experiments were carried out using TBCs as a coating material. We have accumulated the amount of thermal barrier (TD) and a number of thermal fatigue cycles (TFC) under various conditions and combinations of TBC parameters. The Taguchi design based GRG approach was applied in the present investigation to optimize the multi-output of the control parameters of TC for hightemperature applications of TBC coatings. The following conclusions have been formed to summarize the results:

- The evaluation of GRG quantifies the overall performance of control factors of thermal characteristics for TBC coatings lifespan when used in high-temperature applications.

- Taguchi design method based GRA is a very helpful technique for performing multi-output

Table 5 Mean grey relational grade at each level

\begin{tabular}{|c|c|c|c|c|c|c|}
\hline \multirow[t]{2}{*}{ Process parameters } & \multicolumn{4}{|c|}{ Grey relational grade } & \multirow[t]{2}{*}{ Max.-Min. } & \multirow[t]{2}{*}{ Rank } \\
\hline & Level (1) & Level (2) & Level (3) & Level (4) & & \\
\hline Coating Type & 0.3718 & 0.4247 & 0.5390 & 0.7708 & 0.3990 & 1 \\
\hline Coating Side Temperature, ${ }^{\circ} \mathrm{C}$ & 0.4987 & 0.5516 & 0.5568 & 0.4993 & 0.0581 & 4 \\
\hline Coating Thickness, $\mu \mathrm{m}$ & 0.4425 & 0.4860 & 0.5282 & 0.6497 & 0.2072 & 2 \\
\hline Bond Coating Thickness, $\mu \mathrm{m}$ & 0.5251 & 0.5723 & 0.5255 & 0.4834 & 0.0888 & 3 \\
\hline Total mean GRG $=0.5266$ & & & & & & \\
\hline
\end{tabular}




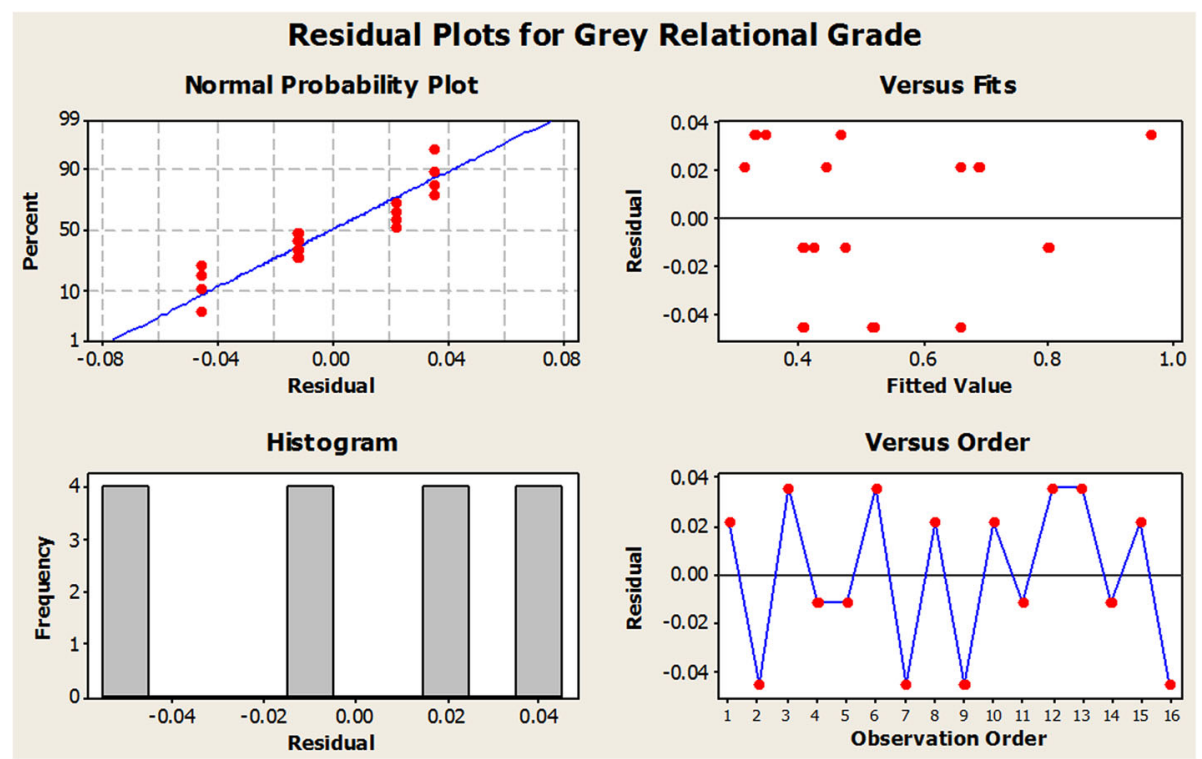

Fig. 3 Residual plots of GRG

optimization to forecast the TD and TFC of TBCs at high temperature applications.

- From the response table, the largest value of the GRG is achieved for the type of coating of Super-Z lloy, coating thickness of $300 \mu \mathrm{m}$, the bond coating thickness of $75 \mu \mathrm{m}$ and temperature on coating side of $1000{ }^{\circ} \mathrm{C}$ for thermal characteristics of TBC coatings for high-temperature applications. These could be recommended levels of TBC coating control parameters for high-temperature applications in the aerospace industry for maximizing thermal barrier/ drop (TD) and thermal fatigue cycles withstood (TFC) considered.

- Results of ANOVA for the grades of the GRA revealed that factor A (coating type) is the principal significant control factor of a thermal characteristic which affects the multi-output characteristics of

Table 6 Results of ANOVA on GRG

\begin{tabular}{lccccccc}
\hline Parameters & DF & SS & Adj MS & F & P & $\begin{array}{c}\text { Contribution } \\
\text { ratio }\end{array}$ \\
\hline Coating Type & 3 & 0.376542 & 0.125514 & 23.71 & 0.014 & 72.98 \\
$\begin{array}{l}\text { Coating Side } \\
\text { Temperature, }{ }^{\circ} \mathrm{C}\end{array}$ & 3 & 0.012243 & 0.004081 & 0.77 & 0.582 & 2.37 \\
$\begin{array}{l}\text { Coating Thickness, } \\
\mu m\end{array}$ & 3 & 0.095492 & 0.031831 & 6.01 & 0.087 & 18.51 \\
$\begin{array}{l}\text { Bond Coat Thickness, } \\
\mu m\end{array}$ & 3 & 0.015810 & 0.005270 & 1.00 & 0.501 & 3.064 \\
Error & 3 & 0.015883 & 0.005924 & - & - & 3.078 \\
Total & 15 & 0.515969 & - & - & - & 100.00 \\
\hline
\end{tabular}

TBCs. The contribution of type of coatings of Super-Z alloy is quite large $72.98 \%$ in comparison to the other set of control factors (coating thickness, bond coat thickness and temperature on coating side) of TBCs used in the aerospace industry. The best performance characteristics were obtained with these set of parameters.

- Confirmation tests/experiments disclosed that the improvement in GRG of an optimal combination of parameters is 0.9628 compared to an initial setting of parameters 0.8168 . The optimum levels of TBC factors can bring several significant enhancements in the control factors.

- Therefore, the GRA based on Taguchi design method can be applied to an optimization of control factors of multi-output performance and using the combination of optimal TC process parameters, necessary improvement in the production of efficient TBCs for high temperature applications can be fulfilled.

Table 7 TBC performance results at high temperature using initial and optimal process parameters

\begin{tabular}{llll}
\hline & $\begin{array}{l}\text { Initial process } \\
\text { parameters }\end{array}$ & \multicolumn{2}{l}{ Optimal process parameters } \\
\cline { 3 - 4 } & A3-T3-C3-B3 & Arediction & Experiment \\
\hline Level & 226 & - & A4-T3-C4-B2 \\
TD & 430 & - & 265 \\
TFC & 0.8168 & 0.9656 & 466 \\
GRG & & & 0.9628 \\
\hline
\end{tabular}




\section{Authors' contributions}

Authors have made substantial contributions to conception, design, in the acquisition of data, and analysis and interpretation of data. Authors participated in drafting the article or revising it critically for important intellectual content.

Authors involved in the final approval of the version to be submitted.

\section{Competing interests}

The authors declare that they have no competing interests.

Received: 22 April 2016 Accepted: 4 October 2016

Published online: 12 October 2016

\section{References}

Cavaliere P, Squillace A, Panella F (2008) Effect of welding parameters on mechanical and micro structural properties of AA6082 joints produced by friction stir welding. J Mater Process Technol 200:364-372

Das DK et al (2014) Properties of ceramic-reinforced aluminium matrix composites-a review. Int J Mech Mater Eng 9(1):1-16

El-Gallab M, Sklad M (1998) Machining of Al/SiC particulate metal matrix composites: Part II: Workpiece surface integrity. J Mater Process Technol 83(1-3):277-285

Gibson BT et al (2004) Friction stir welding: Process, automation, and control. J Manuf Proc 16(1):56-73.

Javadi Y, Sadeghi S, Najafabadi MA (2014) Taguchi optimization and ultrasonic measurement of residual stresses in the friction stir welding. Mater Des 55:27-34

Khalid, Terry (2005) An outsider looks at friction stir welding. Report \#ANM-112N-05

Koilraj M et al (2012) Friction stir welding of dissimilar aluminium alloys AA2219 to AA5083-Optimization of process parameters using Taguchi technique. Mater Des 42:1-7

Lakshminarayanan AK, Balasubramanian V (2007) Process parameters optimization for friction stir welding of RDE-40 aluminium alloy using Taguchi technique. T Nonferr Metal Soc 18:548-554

Lin TR (2002) Optimization technique for face milling stainless steel with multiple performance characteristics. Int J Adv Manuf Technol 19(5):330-335

Mishra RS, Ma ZY (2005) Friction stir welding and processing. Mater Sci Eng R 50:1-78

Mohammed Y, Rahman JF (2011) Optimization of usage parameters of ceramic coatings in high temperature applications using Taguchi design. Int J Eng Sci Tech (IJEST) 3(8):6364-6371

Pan LK et al (2007) Optimizing multiple quality characteristics via Taguchi methodbased Grey analysis. J Mater Process Technol 182(1-3):107-116

Sato YD, Kokawa H (2003) Friction stir welding (FSW) process. Weld Int 17(11):852-853

Sharma P et al (2005) Process parameter selection for strontium ferrite sintered magnets using Taguchi L9 orthogonal design. J Mater Process Technol 168:147-151

Singh H, Kumar P (2004) Tool wear optimization in turning operation by Taguchi method. Indian J Eng Mater Sci 11:19-24

Yunus M, Alsoufi MS (2015) A Statistical Analysis Of Joint Strength Of Dissimilar Aluminium Alloys Formed By Friction Stir Welding Using Taguchi Design Approach, Anova For The Optimization Of Process Parameters. IMPACT: Int J Res Eng Tech (IMPACT: IJRET) 3(7):63-70

Yunus M, Alsoufi MS (2016) Multi-output optimization of tribological characteristics control factors of thermally sprayed industrial ceramic coatings using hybrid Taguchi-grey relation analysis. Friction 3(4):208-216

\section{Submit your manuscript to a SpringerOpen ${ }^{\circ}$ journal and benefit from:}

- Convenient online submission

- Rigorous peer review

- Immediate publication on acceptance

- Open access: articles freely available online

- High visibility within the field

- Retaining the copyright to your article 